\title{
Effect of hydrothermal explosion pretreatment on the composition and structure of Calliandra calothyrsus shrub - a lignocellulosic biomass
}

\author{
Shivanand Yallappa Adaganti ${ }^{1, ~}$, Basavaraj Mahipat Kulkarni ${ }^{2}$, Gururaj Pandurang Desai ${ }^{2}$, \\ Shivappa Shanmukhappa
}

${ }^{1}$ Chemical Engineering Department, SDM College of Engineering and Technology, Dharwad, Karnataka, India

${ }^{2}$ Chemical Engineering Department, Bapuji Institute of Engineering and Technology, Davangere, Karnataka, India

Email address:

shadaganti@gmail.com(S. Y. Adaganti)

To cite this article:

Shivanand Yallappa Adaganti, Basavaraj Mahipat Kulkarni, Gururaj Pandurang Desai, Shivappa Shanmukhappa. Effect of Hydrothermal Explosion Pretreatment on the Composition and Structure of Calliandra Calothyrsus Shrub - a Lignocellulosic Biomass. International Journal of Renewable and Sustainable Energy. Vol. 3, No. 1, 2014, pp. 1-5. doi: 10.11648/j.ijrse.20140301.11

\begin{abstract}
Biomass has been pretreated by hydrothermal explosion using different experimental conditions of temperature between 135 and $173^{\circ} \mathrm{C}$ and operating time of 45 minutes. The effects of hydrothermal explosion conditions have been investigated by measuring chemical compositions (cellulose, hemicelluloses and lignin) in Calliandra calothyrsus. Hydrothermal explosion pretreatment removes the major part of the hemicelluloses, and makes the high cellulose in the solid material for further enzyme hydrolysis. At severity factor of (log Ro) $3.82\left(173^{\circ} \mathrm{C}, 7.5 \mathrm{bar}, 45 \mathrm{~min}\right)$, the biomass fibers contained the significant lowest hemicelluloses and the highest of celluloses at $4.82 \% \mathrm{DW}$ and $58.26 \%$ DW, respectively. Since Calliandra calothyrsus has higher lignin content, lignin structure might be resisting hemicelluloses degradation by hydrothermal explosion pretreatment. Therefore, hydrothermal explosion of lignocellulosic materials to remove hemicelluloses might significantly enhance the efficiency of cellulose hydrolysis.
\end{abstract}

Keywords: Calliandra Calothyrsus, Hydrothermal Explosion, Chemical Compositions

\section{Introduction}

Depletion of world's petroleum supply and greenhouse gas (GHG) effects has resulted in a growing interest in alternate fuels. Main feedstock for ethanol production were sugar crops and starchy biomass, since these raw materials were used for animal and human feeding, so not sufficient for supplying increasing demand. Current research and development is towards using low cost lignocellulosic biomass, a promising renewable alternative source which does not compete with food crops. Lignocellulosic biomass gives a unique and sustainable resource for environmentally safe organic fuels. The digestibility of lignocellulosic biomass is low due to structural features such as lignin content, acetyl groups and crystallinity, which makes direct bioconversion of biomass into sugars by hydrolytic enzymes difficult and unfeasible. Hence, Pretreatment of lignocellulosic biomass is a key step to enhance its digestibility before conversion to biofuel.

Cellulose, hemicellulose and lignin are major structure of lignocellulosic biomass [1]. Complex structure of hemicelluloses and lignin, make the access of cellulase enzymes to cellulose difficult, thus reducing the efficiency of the enzymatic hydrolysis [2]. The efficient bioconversion of lignocellulosic biomass to ethanol is possible with some form of pretreatment. Pretreatment enables effective enzymatic hydrolysis of the cellulose by removal of the surrounding hemicellulose and/or lignin along with modification of the cellulose microfibril structure [3]. Pretreatment has several methods such as physical (mechanical), physico-chemical, chemical and biological pretreatment.

One of the most promising pretreatments appears to be hydrothermal explosion that is physico-chemical pretreatment [4]. Hydrothermal explosion is slightly different from steam explosion [5], which is most attractive pretreatment method for lignocellulosic materials due to no use of chemicals and efficient biomass disruption characteristics. With hydrothermal explosion, solubilization of hemicellulose and separation of lignin can generally be 
achieved by low temperature and high residence time.

In the present study, Calliandra calothyrsus stem was used as raw material. To enhance the accessibility and cellulose content of the biomass, hydrothermal explosion pretreatment was investigated. In this method, Calliandra calothyrsus biomass was loaded in a pressure vessel with water and heated; later the pressure is reduced rapidly, which makes the materials undergo an explosive decompression. Hydrothermal explosion is initiated at a temperature of $152-173^{\circ} \mathrm{C}$ (corresponding pressure $5-7.5$ bar) for 45 minutes before the material is exposed to atmospheric pressure. The explosion also results in substantial breakdown of the lignocellulosic structure along with hydrolysis of the hemicellulosic fraction and depolymerization of the lignin components [6]. Exploded biomass was characterized to study its chemical and morphological properties. The aim of this work was to investigate hydrothermal explosion pretreatment of Calliandra calothyrsus so as to prepare the exploded fibers for enzymatic hydrolysis.

\section{Materials and Methods}

\subsection{Raw Material}

Calliandra calothyrsus stem were obtained from western part of the Karnataka state, India.It is a small, perennial, thornless multistemmed shrub which grows to a height of $3-15 \mathrm{~m}$ and has a trunk diameter of $25-40 \mathrm{~cm}$. During the preparation of the biomass, the stems are first cut into small pieces, dried and then powdered to a size of $3 \mathrm{~mm}$ in our college laboratory. Moisture content of Calliandra calothyrsus was $10.55 \%$.

\subsection{Hydrothermal Explosion Pretreatment}

The hydrothermal-explosion treatments were carried out in a $5-\mathrm{L}$ pilot scale reaction vessel designed to reach a maximum operating pressure of 15 bar. All experiments were carried out using $10 \mathrm{~g}$ dry weight of biomass along with $500 \mathrm{ml}$ of water. Reactor was heated from the bottom, temperature and pressure inside the reactor was monitored during pretreatment. After treatment at given temperature, pressure and residence time, the wet biomass was discharged from the vessel into a collecting tank by rapidly opening a valve, causing the material to expand. The hydrothermal explosion of biomass was evaluated at different temperature $\left(135,152\right.$ and $\left.173^{\circ} \mathrm{C}\right)$, pressure $(2.5,5$ and 7.5 bar) for time period of $45 \mathrm{~min}$. The severity of the treatment was represented by a single term Ro [7] which associates the effect of residence time ( $t, \mathrm{~min})$ and temperature of reaction $\left(T,{ }^{\circ} \mathrm{C}\right): \mathrm{Ro}=t \exp (T-100 / 14.75)$ The log value of Ro gives the severity factor that is used to map the effects of hydrothermal explosion pretreatment on biomass.

Severity factor $=\log ($ Ro $)--(1)$

Value of $\log$ Ro for different pretreatment conditions is shown in Table 1. The hydrothermal explosion fibers (HEF) were packed into a plastic bag and stored in a cold room, the solids content of fibers sample was determined.

\subsection{Characterization of Biomass}

Scanning electron micrograph (SEM) (Hitachi S- 4800, Tokyo, Japan) instruments were used for the microstructural analysis of Calliandra calothyrsus samples. Fourier transform infrared (FTIR) spectrophotometer (Tensor 27; Bruker, Germany) was used to determine the changes in functional groups of biomass caused by the treatments, FTIR spectra were recorded in transmittance mode within the range of 4000 to $500 \mathrm{~cm}^{-1}$.

\subsection{Chemical Compositions Analysis}

The chemical composition of raw and hydrothermal exploded biomass (\% dry weight) was determined using the Technical Association of the Pulp and Paper Industry (TAPPI) standards [8]. First, the biomass sample was prepared and extracted with ethanol-benzene, according to TAPPI, T $257 \mathrm{~cm}-02$ and T $204 \mathrm{~cm}-07$. Then, the chemical analyses of biomass were conducted. The acid insoluble lignin (Klason lignin) was determined, extracting in a sulfuric acid of $72 \%$ by TAPPI T-222 om- 06 . Cellulose and hemicellulose were determined according to the procedures described by Goering and Van Soest (1970) [9].

\section{Results \& Discussion}

\subsection{Chemical Composition}

Chemical compositions of untreated and hydrothermalexploded Calliandra calothyrsus are shown in Table 1.In lignocellulosic structure, cellulose fibers are within ligninpolysaccharide matrix. It is observed that during various pretreatment conditions, the biomass solubilize, fractionate, hydrolyze and separates hemicelluloses, cellulose and lignin.

Table 1. Chemical Compositions of untreated and hydrothermal-exploded Calliandra calothyrsus (\% of dry wt.)

\begin{tabular}{lcccc}
\hline \multicolumn{1}{c}{ Sample } & Cellulose & Hemicellulose & Lignin & $\begin{array}{c}\text { Severity } \\
\text { factor }\end{array}$ \\
\hline $\begin{array}{l}\text { Untreated } \\
135^{\circ} \mathrm{C}, 2.5\end{array}$ & 44.54 & 19.35 & 27.31 & -- \\
bar, $45 \mathrm{~min}$ & 46.32 & 12.6 & 28.18 & 2.68 \\
$\begin{array}{l}152^{\circ} \mathrm{C}, 5 \text { bar, } \\
45 \mathrm{~min}\end{array}$ & 54.68 & 7.32 & 32.24 & 3.18 \\
$\begin{array}{l}173^{\circ} \mathrm{C}, 7.5 \\
\text { bar,45 min }\end{array}$ & 58.26 & 4.82 & 35.56 & 3.82 \\
\hline
\end{tabular}

Table 1 shows that cellulose content increased with an increase in temperature and pressure, because sever conditions causes $\beta$-glycosidic bonds between D-glucosyl groups of cellulose to rupture, which results in breakage of cellulose. Solubilization increased as pretreatment conditions were drastic, so the cellulose in treated biomass varied from $46.32 \%$ to $58.26 \%$ depending upon severity. 
Whereas the hemicellulose content in the fiber after hydrothermal explosion from all samples decreased with the increase in severity factor. For 3.82 severity factor hemicelluloses removal was found to be $75 \%$. This attributes that hydrothermal explosion preferentially

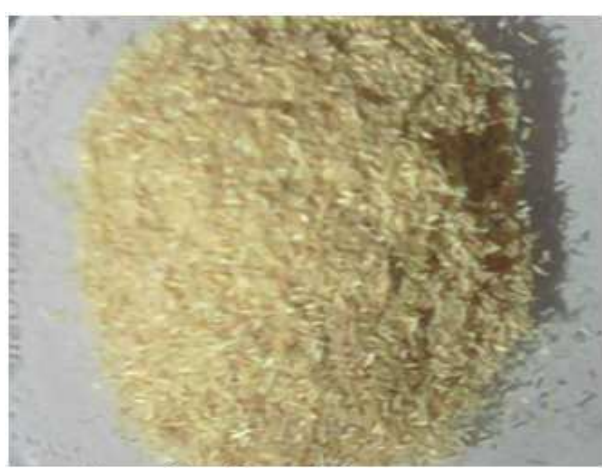

(a) Calliandra calothyrsus

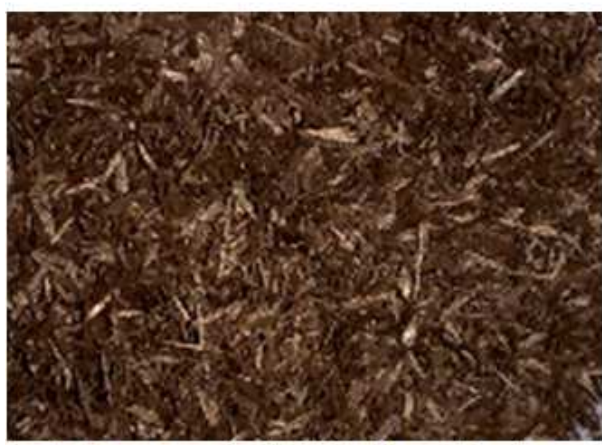

(c) Pretreated at $152^{\circ} \mathrm{C}, 5$ bar, $45 \mathrm{~min}$ affected the hemicelluloses by solubilizing it [10]. Most of hemicelluloses were hydrolyzed into sugars and metabolites (furfural, HMF and acetic acid), which might have washed with hot water.

Figure 1. Images of Calliandra calothyrsus before and after hydrothermal explosion pretreatment

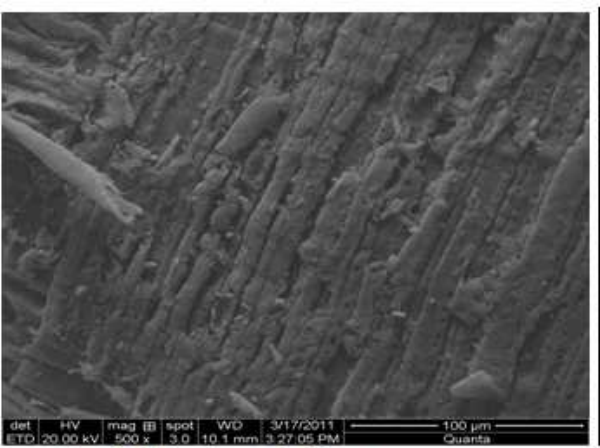

(a) Calliandra calothyrsus

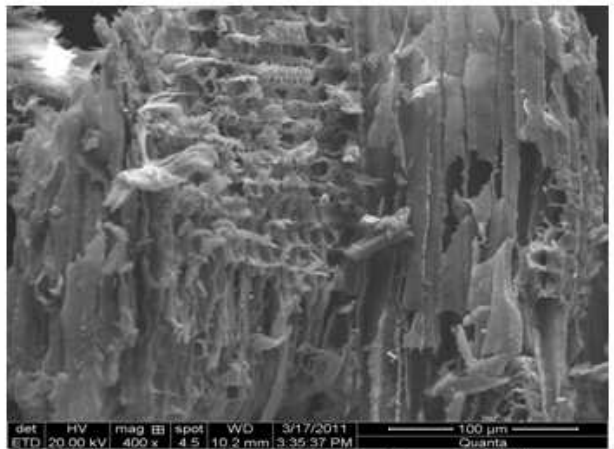

(c) Pretreated at $152^{\circ} \mathrm{C}, 5$ bar, $45 \mathrm{~min}$

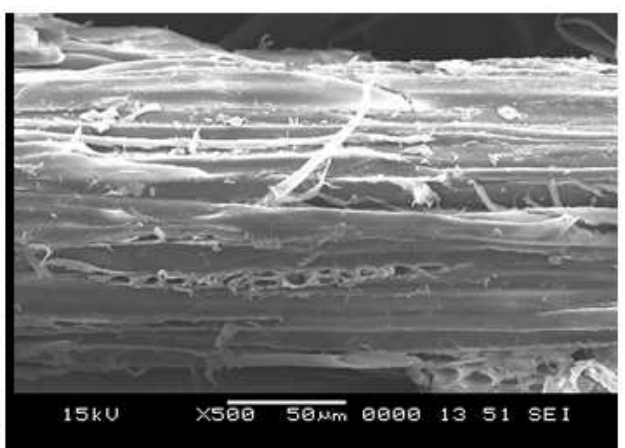

(b) Pretreated at $135^{\circ} \mathrm{C}, 2.5$ bar, $45 \mathrm{~min}$

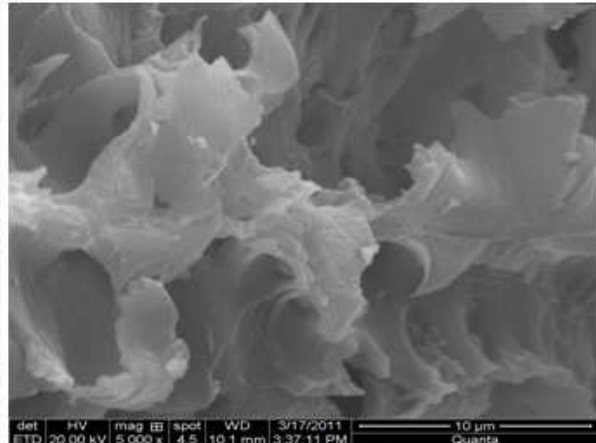

(d) Pretreated at $173^{\circ} \mathrm{C}, 7.5$ bar, $45 \mathrm{~min}$

Figure 2. SEM images of fibers before and after hydrothermal explosion pretreatment 


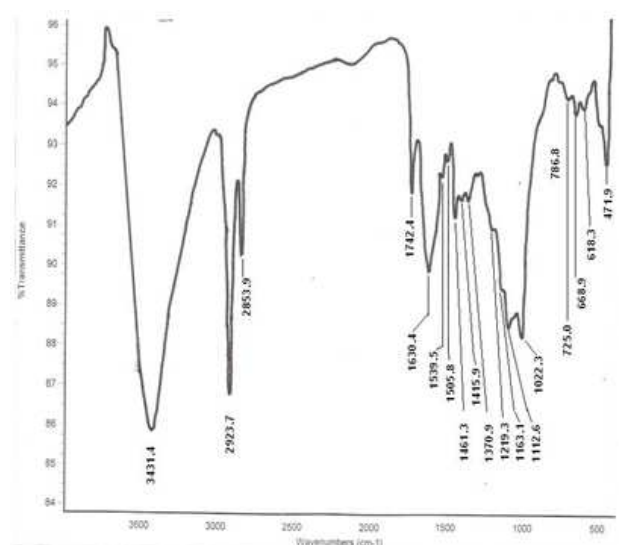

(a) untreated

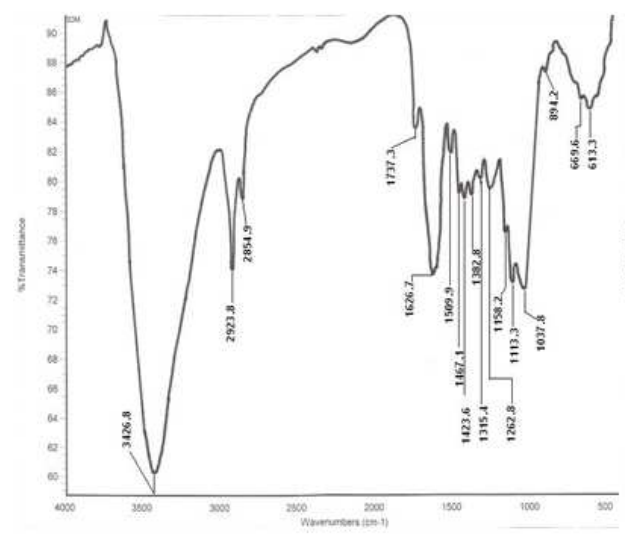

(c) Treated at $152^{\circ} \mathrm{C}, 5 \mathrm{bar}, 45 \mathrm{~min}$.

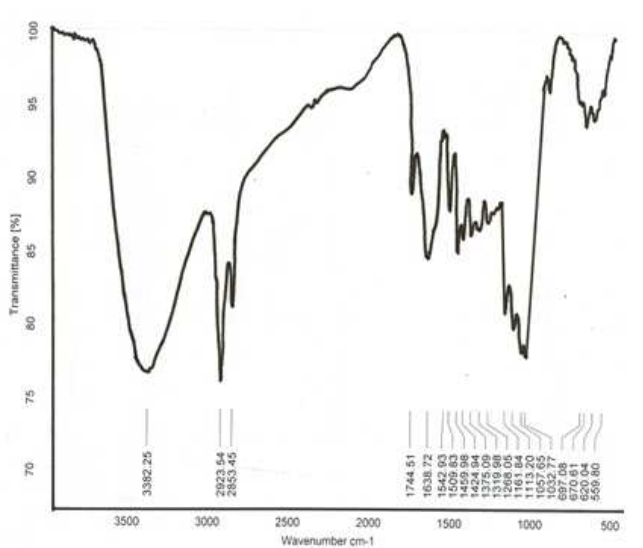

(b) Pretreated at $135^{\circ} \mathrm{C}, 2.5 \mathrm{bar}, 45 \mathrm{~min}$

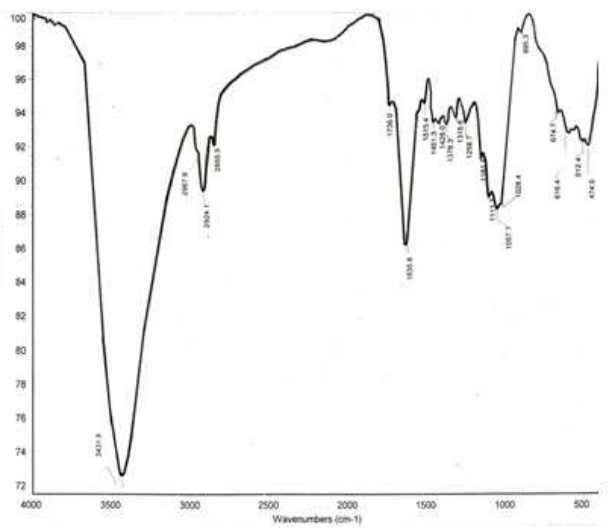

(d) Treated at $173^{\circ} \mathrm{C}, 7.5$ bar, $45 \mathrm{~min}$

Figure 3. FTIR spectra of Calliandra calothyrsus

\subsection{Morphology of Calliandra calothyrsus Under Various Hydrothermal Explosion Treatments}

Figure 1 shows the images of hydrothermal explosion of Calliandra calothyrsus particles at various conditions. Volume of fibers increased after the hydrothermal explosion process, the reason for this was due to rapid thermal expansion of fibers which has helped to open up the rigid and highly ordered biomass structure by disrupting the middle lamella lignin.

Figure 2(a) shows the SEM images of raw Calliandra calothyrsus fibrous structure which is common in most biomass. SEM images of biomass after explosion were used to investigate the structure of these fibers. Figure 2(b), 2(c) and 2(d) shows structural breakdown of the biomass which in turn has increased the pore size of the material however they were still found to be fibrous after the hydrothermal treatment. Images clearly demonstrate that more fibers break open with increase in temperature and pressure.

SEM image Figure 2(b) at hydrothermal explosion at $135^{\circ} \mathrm{C}$ did not show opening up of fibers, whereas with the increasing severity at $152^{\circ} \mathrm{C}$ and $173^{\circ} \mathrm{C}$ more fibers were burst open (Figure 2(c)and(d)), which shows that pretreatment of a biomass made a substantial change in porous structure and broken down many fibers simultaneously. So cellulose became more porous and loose. Due to existence of porous structure, the enzyme could penetrate into cellulose and contact the interior structure of cellulosic biomass more easily, which increase the yield of sugars by enzymatic hydrolysis.

\subsection{FTIR}

FTIR spectroscopy was used to examine changes occurred in the chemical constituents of the biomass fibers, before and after hydrothermal explosion. Figure 3 shows FTIR spectrum of raw and exploded Calliandra calothyrsus fibers. The peaks in the range 3700 to $3400 \mathrm{~cm}^{-}$ ${ }^{1}$ corresponds to $\mathrm{O}-\mathrm{H}$ stretching band, which was due to the vibrations of hydrogen-bounded hydroxyl group, whereas around $2950-2900 \mathrm{~cm}^{-1}$ were due to the stretching of C-H [11] [12]. The peak at 1736-1744 attributes to acetyl group or uronic ester groups of hemicelluloses. Figure $3 b, 3 c$ and $3 \mathrm{~d}$ shows that the peak almost disappeared in the spectra of hydrothermally exploded biomass, which indicates that most of the hemicelluloses were removed during pretreatment. The peak at $1630 \mathrm{~cm}^{-1}$ may be due to bending mode of absorbed water.

The band around $1510 \mathrm{~cm}^{-1}$ indicates aromatic skeleton vibration of lignin fraction. The peaks around 1375 
represent $\mathrm{C}-\mathrm{H}$ asymmetric deformation. The peaks in the region of 1200 to $1059 \mathrm{~cm}^{-1}$ represent the $\mathrm{C}-\mathrm{O}$ stretch band and deformation bands in lignin, cellulose and residual hemicelluloses [11]. The peaks that vibrated between 894 $895 \mathrm{~cm}^{-1}$ are assigned to cellulose structure ( $\beta$-glycosidic linkages between glucose ring of cellulose) [13]

\section{Conclusions}

1 This study illustrates changes in the composition and structure of raw Calliandra calothyrsus biomass using hydrothermal explosion pretreatment.

2 The results show that cellulose content increased from $44.54 \%$ to $58.26 \%$, whereas large fraction of hemicelluloses was lost decreasing its content from $19.35 \%$ to $4.82 \%$ at higher pretreatment condition.

3 SEM images revealed that biomass became more porous and loose, indicating higher specific surface under sever hydrothermal explosion.

$4 \quad$ FTIR illuminated clear accessible of cellulose at higher explosion condition, from Figure $3 c$ and $3 d$ at around $894 \mathrm{~cm}^{-1}$.

\section{References}

[1] Schultz T.P., Blermann C.J., McGlnnis G.D., Steam Explosion of Mixed Hardwood Chips as a Biomass Pretreatment, Industrial \& Engineering Chemistry Product Research and Development, 1983,22,344 - 348.

[2] Mussatto S.I., Fernandes M., Milagres A.M.F., Roberto I.C.,Effect of hemicellulose and lignin on enzymatic hydrolysis of cellulose from brewer's spent grain, Enzyme and Microbial Technology, 2008, 43,124 - 129.

[3] Knauf M and Moniruzzaman M., Lignocellulosic biomass processing: A perspective,International Sugar Journal, $2004,106,1263,147-150$.

[4] Spait H.A., American Chemical Society Ser. 1977, 43, 193
[5] McMillan, JD, 1994, Pretreatment of lignocellulosic biomass, In: Mosier N., Wyman C., Dale B., Elander R., Lee Y.Y., Holtzapple M., \& Ladisch M 2005, Features of promising technologies for pretreatment of lignocellulosic biomass, Bioresource Technology,96,673 - 686

[6] Cara C., Ruiz E., Ballesteros I, Negro M.J., Castro E., Enhanced enzymatic hydrolysis of olive tree wood by steam explosion and alkaline peroxide delignification, Process Biochemistry, 2006, 41, 423 - 429.

[7] Heitz M., Capek-Ménard E., Koeberle P., Cagné J., Chornet E., Fractionation of Populus tremuloides at the pilot plant scale: optimization of steam pretreatment conditions using the Stake II technology, Bioresource Technology, 1991, 35, $23-32$.

[8] TAPPI Standard, T $204 \mathrm{~cm}-07$, Solvent extractives of wood and pulp, 1998 TAPPI Standard T 222 om-06, Acid insoluble lignin in wood and pulp, 2011 TAPPI Standard T $257 \mathrm{~cm}-02$, Sampling and preparing wood for analysis, 2002

[9] Goering H. K., and Van Soest P.J., Forage Fiber Analysis (Apparatus, Reagents, Prosedures and some Applications),United States Department of Agriculture (USDA) 1970, Agricultural Handbook No. 379: 20

[10] Ballesteros I.,Oliva J.M., Negro M.J., Manzanares P., and Ballesteros M., Enzymatic hydrolysis of steam exploded herbaceous agricultural waste (Brassica carinata) at different particles sizes, Process Biochem. 2002, 38(2), 187-192

[11] Sun X.F., Xu F., Sun R.C., Fowler P., and Baird M.S., Characteristics of degraded cellulose obtained from steamexploded wheat straw, Carbohyd. Res. 2005, 340(1), 97-106.

[12] Kaushik A., Singh M. Isolation and characterization of cellulose nanofibrils from wheat straw using steam explosion coupled with high shear homogenization, Carbohyd. Res., 2011,346(1), 76-85.

[13] Jonoobi M., Harun J., Shakeri A., Misra M., and Oksman K., Chemical composition,crystallinity and thermal degradatuion of bleached and unbleached kenaf bast (Hibiscus cannabinus) pulp and nanofibers, Bioresources,2009,4(2),626-639 